\title{
Review Article \\ The Hydrolysis of Carbonyl Sulfide at Low Temperature: A Review
}

\author{
Shunzheng Zhao, Honghong Yi, Xiaolong Tang, Shanxue Jiang, Fengyu Gao, Bowen Zhang, \\ Yanran Zuo, and Zhixiang Wang
}

Department of Environmental Engineering, College of Civil and Environmental Engineering,

University of Science and Technology Beijing, Beijing 100083, China

Correspondence should be addressed to Honghong Yi; yihonghong@tsinghua.org.cn

Received 16 May 2013; Accepted 19 June 2013

Academic Editors: S. Niranjan, L. Wang, and Q. Wang

Copyright (C) 2013 Shunzheng Zhao et al. This is an open access article distributed under the Creative Commons Attribution License, which permits unrestricted use, distribution, and reproduction in any medium, provided the original work is properly cited.

\begin{abstract}
Catalytic hydrolysis technology of carbonyl sulfide (COS) at low temperature was reviewed, including the development of catalysts, reaction kinetics, and reaction mechanism of COS hydrolysis. It was indicated that the catalysts are mainly involved metal oxide and activated carbon. The active ingredients which can load on COS hydrolysis catalyst include alkali metal, alkaline earth metal, transition metal oxides, rare earth metal oxides, mixed metal oxides, and nanometal oxides. The catalytic hydrolysis of COS is a first-order reaction with respect to carbonyl sulfide, while the reaction order of water changes as the reaction conditions change. The controlling steps are also different because the reaction conditions such as concentration of carbonyl sulfide, reaction temperature, water-air ratio, and reaction atmosphere are different. The hydrolysis of carbonyl sulfide is base-catalyzed reaction, and the force of the base site has an important effect on the hydrolysis of carbonyl sulfide.
\end{abstract}

\section{Introduction}

With the rapid development of ecomy, energy supply and demand have become increasingly prominent; the scientific use of high-sulfur energy received extensive attention. Among the chemical raw material gases, which are made from coal, oil and natural gas, sulfur compounds can generally be divided into two major categories of organic sulfur and inorganic sulfur. Organic sulfur contains carbonyl sulfide (COS), carbon disulfide $\left(\mathrm{CS}_{2}\right)$, thiophene, mercaptan, and so forth [1]. Inorganic sulfur is mainly hydrogen sulfide $\left(\mathrm{H}_{2} \mathrm{~S}\right)$. COS, accounted for approximately $80 \%$ to $90 \%$ of the total organic sulfur, is normally regarded as a significant poison which can cause the deactivation of the industrial catalyst. Even only a trace amount of COS can result in the deactivation of catalysts and can lead to corrosion of reaction equipments [2-4]. For instance, as little as $4 \mathrm{mg}$ of sulfur per gram of catalyst on the surface of the $\mathrm{Fe}-\mathrm{Cu}$ $\mathrm{K}$ catalyst decreases the activity by ca. $50 \%$ in the FischerTropsch process [5]. Furthermore, not only does COS cause economic loss, but also affects the environment. COS is thought to be the most abundant sulfur-containing gas in the troposphere. Apart from volcanic injection, tropospheric $\mathrm{COS}$ is the main source of sulfur in the stratosphere leading to the stratospheric sulfate layer. The reactions of $\mathrm{H}, \mathrm{OH}$, and $\mathrm{O}(3 \mathrm{P})$ with COS are known as important chemical sinks for consumption of this compound [6]. It has been proved to be a major source of acid rain when oxidized to sulfur oxide and to promote photochemical reactions [7-9]. In addition, in the past decades, much attention was drawn to the sources and sinks of carbonyl sulfide (COS) in the atmosphere due to the important role of COS in the formation of stratospheric sulfate aerosols [10-15]. Therefore, the removal of carbonyl sulfide is the main problem to solve in the process of feed gas deep purification.

Currently, the principal methods of carbonyl sulfide removal include hydrogenation, hydrolysis, absorption, adsorption, photolysis, and oxidation, [16-22]. Hydrolysis method, which has the advantages of low reaction temperature, no consumption of the hydrogen source, and few side effects, attracts a lot of researches at home and abroad. Carbonyl sulfide hydrolysis research mainly includes two 
aspects: (1) research and development of hydrolysis catalyst; (2) research on reaction kinetics and mechanism. The two complement each other and promote each other. The preparation of the catalyst is to use a suitable carrier load on a certain amount of an active ingredient. At present, the carriers of COS hydrolysis catalysts mainly contain two categories: (1) metallic oxides, including a composite metal oxide such as $\gamma-\mathrm{Al}_{2} \mathrm{O}_{3}, \mathrm{TiO}_{2}$ and manganese iron composite metal oxides; (2) nonmetallic oxides, mainly refer to activated carbon. Active ingredients which can load on the carrier include alkali metal, alkaline earth metal, transition metal oxides, rare earth metal oxides, mixed metal oxide, and nanoscale metal oxides. Some catalysts with relatively superior performance have been researched and developed at home and abroad so far.

The researches on reaction kinetics and mechanism not only can accelerate the development of hydrolysis catalyst with good performance and high activity, but also can provide a theoretical basis for the reactor design. Consequently, domestic and foreign researchers researched and developed catalyst. They also studied the carbonyl sulfide hydrolysis reaction kinetics and mechanism and made a number of research achievements.

In this paper, the development of catalyst for carbonyl sulfide catalytic hydrolysis, reaction kinetics, and reaction mechanism has been summarized systematically.

\section{Catalysts for COS Hydrolysis}

2.1. Catalyst Carrier. Great catalyst carrier should have proper specific surface area, good heat resistance, and mechanical strength. At the moment, COS hydrolysis catalyst carrier basically has two kinds. One is a delegate with $\mathrm{Al}_{2} \mathrm{O}_{3}$ and $\mathrm{TiO}_{2}$ metal oxides. Another kind of non-metallic oxide is a delegate with activated carbon. In addition, with the development of material science, the researchers also have developed many new types of catalyst carrier, such as cordierite.

2.1.1. Metal Oxide. Metallic oxide carrier of COS hydrolysis catalyst refers mainly to $\mathrm{Al}_{2} \mathrm{O}_{3}$ and $\mathrm{TiO}_{2}$. In addition, $\mathrm{Fe}$ $\mathrm{Mn}$ metal oxides have obtained the good effect in COS removal. Among them, the $\mathrm{Al}_{2} \mathrm{O}_{3}$ as the present study more in-depth and widely used catalyst has some characteristics of large specific surface area, high surface activity, good thermal stability, and so forth. $\mathrm{Al}_{2} \mathrm{O}_{3}$ itself has a certain activity for the hydrolysis of COS. The patent CN1069673 introduces a kind of $\mathrm{Al}_{2} \mathrm{O}_{3}$ catalyst in which COS hydrolysis conversion rate would be $51.2 \%$ under the condition of not adding any additives $[28,29]$. However, this kind of catalyst sulphate resistance is poorer. We increase surface alkali center number and intensity by dipping a certain amount of alkaline components on the surface to that further improve the COS hydrolysis activity and to improve the service life and the catalytic properties such as resistance to poisoning [30]. $\mathrm{Al}_{2} \mathrm{O}_{3}$ itself is same as $\mathrm{TiO}_{2}$ to have COS hydrolysis function, and its sulfate resistance is better than $\mathrm{Al}_{2} \mathrm{O}_{3}$.

The catalyst with $\mathrm{TiO}_{2}$ as the carrier has a great activity, and high mechanical strength at low temperature [31].

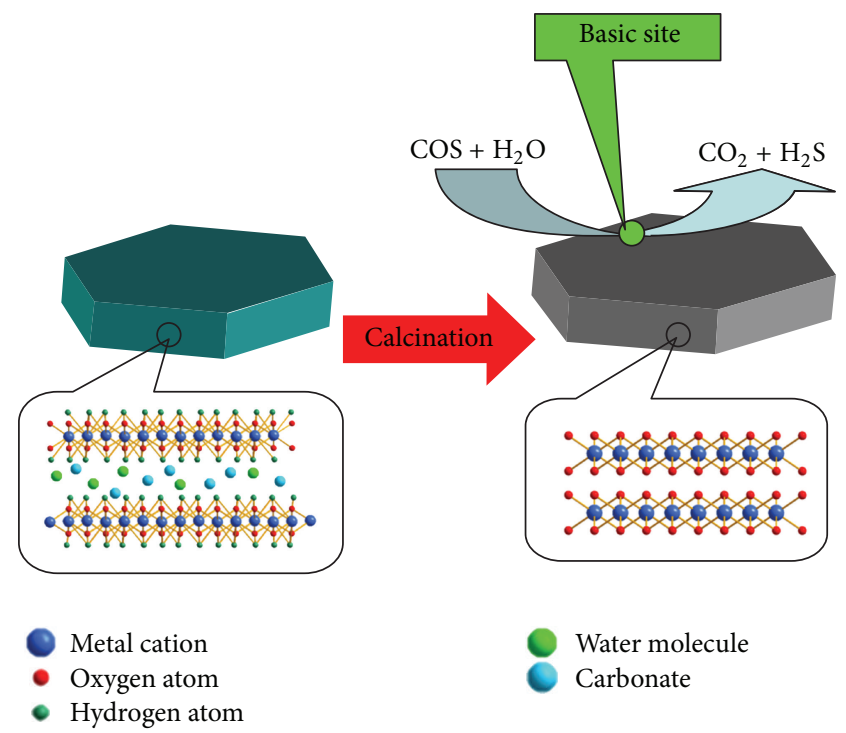

FIGURE 1: Hydrolysis of COS on the hydrotalcite-derived oxides.

Although the specific surface area of $\mathrm{TiO}_{2}$ is low, the price is high; it is not an easy molding industry, and the industrial applications are chief based on $\mathrm{Al}_{2} \mathrm{O}_{3}$ catalyst. However, by a small amount of $\mathrm{TiO}_{2}$ modulation, the $\mathrm{Al}_{2} \mathrm{O}_{3}$ catalyst ability greatly enhanced resistance to sulfur poisoning. Composite carrier was found that it is of granular distribution and good dispersion by scanning electron microscope.

In recent years, the mixed oxides derived from hydrotalcite-like compounds (HTLCs) as catalysts received much attention in view of their unique properties [32]. HTLCs, also known as layered double hydroxides (LDHs), are a family of anionic clays. The chemical composition can be represented by the following general formula: $\left[\mathrm{M}(\mathrm{II})_{1-x} \mathrm{M}(\mathrm{III})_{x}(\mathrm{OH})_{2}\right]^{x+}$ $\left(\mathrm{A}^{n-}\right)_{x / n} \cdot \mathrm{mH}_{2} \mathrm{O}$, where $\mathrm{M}(\mathrm{II})$ and $\mathrm{M}(\mathrm{III})$ are divalent and trivalent cations in the octahedral positions within the hydroxide layers, $x$ is the molar ratio $\mathrm{M}(\mathrm{III}) / \mathrm{M}_{\text {total }}$, and its value ranges between 0.17 and $0.33 . \mathrm{A}^{n-}$ is an exchangeable interlayer anion $[33,34]$. HTLCs calcined at high temperatures will lose crystal water, and the interlayer anions and hydroxyl will be removed too. Therefore, the hydrotalcitelike layered structures will be destroyed, the surface area will increase, and the metal oxides are obtained.

In our previous studies, we found that the mixed oxide derived from HTLCs is a kind of potential catalysts for the hydrolysis of COS at low temperature (Figure 1). The catalyst performance was strongly related to the synthesis of $\mathrm{pH}$ and calcination temperature. In general, COS was hydrolyzed to $\mathrm{H}_{2} \mathrm{~S}$, which is depending on the chemistry of the derived oxides. The end products of hydrolysis were simple substance $S$ and sulfate. The presence of oxygen will accelerate the formation of the final product [35-43].

2.1.2. Activated Carbon. Activated carbon has become to be an ideal catalyst carrier because of its high specific surface area, the large pore volume, the large variety of surface functional groups, and good electron conductivity. However, the activity to remove COS for unmodified activated carbon 
is very low and its sulfur capacity is small; therefore, it must be modified. Activated carbon has not only excellent COS conversion rate, but also can remove $\mathrm{H}_{2} \mathrm{~S}$ effectevily by using carbonates and other active ingredients to modify [44]. The 3018 desulfurizer developed by Dalian Institute of Chemical Physics showed a better removal COS performance at a temperature of about $80^{\circ} \mathrm{C}$, the product was elemental sulfur $[45,46]$.

In our previous study, a series of microwave coal-based active carbon catalysts loaded by metal oxides were prepared by a sol-gel method and tested for the catalytic hydrolysis of COS at relatively low temperatures. The influences of preparation conditions on catalytic activity were studied, which were the kinds and amount of additive, calcination temperatures, and types and content of alkali [47-51].

2.1.3. Special Carrier. Yan et al. have used honeycomb cordierite as the carrier in the experiment [52]. The cordierite was polished to form the pillar-shaped carrier, the desulfurizer which was made by using the method of dipping to make $\mathrm{Al}_{2} \mathrm{O}_{3}$ slurry load cordierite exhibit good desulfurization effect. The result indicated the following: COS hydrolysis activity gradually increases with the increase of the loading of $\gamma-\mathrm{Al}_{2} \mathrm{O}_{3}$ and $\mathrm{La}(\mathrm{OH})_{3}$ at low temperatures; airspeed has greater impact on the activity of the catalyst; $\mathrm{La}-\mathrm{Al} /$ honeycomb cordierite catalyst has good antioxidant properties; the presence of $\mathrm{O}_{2}$ made the single loaded $\gamma$ $\mathrm{Al}_{2} \mathrm{O}_{3}$ catalyst lose some activation, while the catalyst which was combined with La-Al has not been affected; it indicated that $\mathrm{La}(\mathrm{OH})_{3}$ is $\mathrm{COS}$ hydrolysis catalyst which has higher antioxidant.

\subsection{Active Ingredients}

2.2.1. Alkali Metal and Alkaline Earth Metal. Alkali metal and alkaline earth metal which are supported on $\gamma-\mathrm{Al}_{2} \mathrm{O}_{3}$ can modulate the distribution of the amount of alkali and base intensity, and they played slightly different roles: the alkali metal can modulate the amount of alkali apparently, while the alkaline earth metal can modulate the distribution of base intensity apparently.

George et al. found that a small amount of $\mathrm{NaOH}$ plays a significant role in promoting the COS hydrolysis; the initial rate of $\mathrm{Co}-\mathrm{Mo} / \mathrm{Al}_{2} \mathrm{O}_{3}$ catalyst which was impregnated by $3.9 \% \mathrm{NaOH}$ can increase by 25 times at $230^{\circ} \mathrm{C}$ [23]. Li and Tan et al., and so forth, prepared a series of catalysts by using oxides which were impregnated with alkali metal and alkaline earth metal, and they sorted the catalytic activity by doing experiments: $\mathrm{Cs}_{2} \mathrm{O} / \gamma-\mathrm{Al}_{2} \mathrm{O}_{3}>\mathrm{K}_{2} \mathrm{O} / \gamma-\mathrm{Al}_{2} \mathrm{O}_{3}, \mathrm{BaO} / \gamma$ $\mathrm{Al}_{2} \mathrm{O}_{3}>\mathrm{Na}_{2} \mathrm{O} / \gamma-\mathrm{Al}_{2} \mathrm{O}_{3}$, and $\mathrm{CaO} / \gamma-\mathrm{Al}_{2} \mathrm{O}_{3}>\mathrm{MgO} / \gamma-\mathrm{Al}_{2} \mathrm{O}_{3}$. The catalytic activity was also related to the amount of loaded metal oxides, and the activity reached the highest when the mole fraction is about $5 \%[53,54]$.

2.2.2. Transition Metals, Composite Metal Oxides, and Nanometals. Tong associated the activity of $\mathrm{Al}_{2} \mathrm{O}_{3}$ catalyst (a transition metal) with the position of transition metal promoter $\mathrm{M}$ in the periodic table, found the relationship of catalyst activity and the combination ability of the M-S bond, and concluded that Iron as the active component of the catalyst on the COS has the highest catalytic activity [55]. West et al. loaded a series of metal ions $\left(\mathrm{Fe}^{3+}, \mathrm{Co}^{2+}, \mathrm{Ni}^{2+}\right.$, $\mathrm{Cu}^{2+}$, and $\mathrm{Zn}^{2+}$ ) to the $\mathrm{Al}_{2} \mathrm{O}_{3}$ plate. It was shown that $\mathrm{Cu}^{2+}$ has the catalyst activity only at the beginning of the reaction $[56,57]$. In addition, researchers found that loading a variety of active components to the unified carrier can achieve better results. Wang et al. investigated a ferromanganese composite metal oxide by the coprecipitation method. It was shown that this desulfurizer has high-precision removal of COS and larger sulfur capacity in a strong reducing atmosphere. They also found that the desulfurization accuracy of the catalyst is greatly improved, while the nickel oxide and cerium oxide are added. The COS concentration of the outlet was less than $0.1 \times 10^{-6}$; adding zinc oxide achieved a greater improvement of sulfur capacity [58]. With the development of nanotechnology, nanomaterials has began to be applied to the development of COS hydrolysis catalyst. Gao et al. investigated catalyst with $\alpha$ - $\mathrm{FeOOH}$ nanoparticles as the active ingredient, which was prepared by homogeneous precipitation method, the ammonia titration. They found that it has a good effect on the COS hydrolysis and a high activity under the condition of low temperature and high space velocity. Two series of catalysts achieved the $100 \%$ conversion of $\mathrm{COS}$ at the temperature of $60^{\circ} \mathrm{C}$ and $40^{\circ} \mathrm{C}-$ $45^{\circ} \mathrm{C}$, respectively, $[59,60]$.

2.2.3. Rare Earth Metal Oxides. Colin Rhodesa et al. studied the synergistic effects of rare earth elements and alkaline rare earth accelerator on the $\mathrm{Al}_{2} \mathrm{O}_{3}$ plate. Through the analysis of DRIFT spectrum, it was shown that the role of hydroxyl groups on the surface composite catalyst is similar to pure $\mathrm{Al}_{2} \mathrm{O}_{3}$, and it was concluded that accelerator can provide high stable cation to the catalyst [61]. Zhang et al. initially investigated the hydrolytic activity of the rare earth series of sulfur oxides and divided the rare earth oxides into three categories, according to hydrolytic activity of COS: (1) high hydrolytic activity: La, Pr, Nd, and Sm; (2) high hydrolytic activity: Eu; (3) low hydrolytic activity: Ce, Gd, Dy, Ho, and $\mathrm{Er}$, with the following order: $\mathrm{La} \approx \mathrm{Pr} \approx \mathrm{Nd} \approx \mathrm{Sm}>\mathrm{Eu}>$ $\mathrm{Ce}>\mathrm{Gd} \approx \mathrm{Ho}>\mathrm{Dy}>$ Er. In addition, rare earth sulfur oxides showed a good oxidation resistance. Some researchers found that increasing temperature is conducive to improve the antioxidant capacity of the catalyst, but a certain amount of $\mathrm{SO}_{2}$ will lead to a decrease in catalyst activity, and it is a reversible inactivation [62-64].

\section{Reaction Kinetics of COS Hydrolysis}

Researches on catalytic hydrolysis reaction kinetics of carbonyl sulfide include establishing the kinetic equations of chemical reactions and determining the controlling step of hydrolysis. Dynamic models reported in articles are different because of the difference in research conditions.

At present, most researchers hold that the catalytic hydrolysis of COS is a first-order reaction with respect to carbonyl sulfide, while the reaction order of water changes as the reaction conditions change. The controlling steps are also 
different because the reaction conditions such as concentration of carbonyl sulfide, reaction temperature, water-air ratio, and reaction atmosphere are different.

Fiedorow et al. [65] studied the hydrolysis of carbonyl sulfide on pure alumina and base modified alumina, respectively. They concluded that the catalytic hydrolysis of carbonyl sulfide is a first-order reaction with respect to carbonyl sulfide and a zero-order reaction with respect to water. George [66] also reached the same conclusion by studying the hydrolysis of carbonyl sulfide on Co-Mo-Al catalyst.

Tong et al. [67] studied the hydrolysis of carbonyl sulfide under medium temperature conditions and concluded that the catalytic hydrolysis of carbonyl sulfide is a first-order reaction with respect to carbonyl sulfide, while the reaction order of water is influenced by the partial pressure of water. When the partial pressure of water is $0.1-0.26$, the reaction order of water is 0.4 . When the pressure is higher than 0.26 , the reaction order of water is -0.6 . The controlling step under low temperature is the adsorption of carbonyl sulfide or the formation of reaction intermediated by adsorbed carbonyl sulfide and water. Chan and Dalld [68] studied the hydrolysis of carbonyl sulfide on Kaiser Kas201 catalyst. They adopted the single factor experiment method and drawn the same conclusion as Miroslav et al. [69] who studied the hydrolysis reaction kinetics of carbonyl sulfide on Co-Mo-Al catalyst and $\mathrm{Al}_{2} \mathrm{O}_{3}$ catalyst. They concluded that when the reaction temperature is 150 centigrade and when the volume fraction of carbonyl sulfide, hydrogen sulfides and carbon dioxide are $0.22 \%, 0.1 \%$, and $0.01 \%$, respectively, the hydrolysis rate remains unchanged as the fraction of water vapour increases from $0.2 \%$ to $2.5 \%$. Thus, the reaction order of water is zero.

Liang et al. [70] studied the hydrolysis of carbonyl sulfide on TGH-2 catalyst and found that when the water-air ratio is greater than 80 , the reaction order of water is negative. Their explanation is that the micropore is blocked due to its condensation, so the reaction process cannot continue. Lin et al. [71] studied the hydrolysis of carbonyl sulfide under the conditions of low reaction temperature, high water-air ratio, and low carbonyl sulfide concentration. They concluded that the reaction order of carbonyl sulfide is 1 , while the reaction order of water is -0.5 . In other words, when the concentration of carbonyl sulfide is low, it will impede the hydrolysis process. Their explanations are that the condensation of water vapor blocks the pore of the catalyst and the two reaction sites are competitive, in which the adsorption of water on the basic site results in the decrease of catalytic activity. They held that the adsorption of carbonyl sulfide is dissociative and the adsorption isotherm corresponds with the Freundlich equation. In other words, the adsorption of carbonyl sulfide is the controlling step of the reaction.

Guo et al. [72] studied the hydrolysis of carbonyl sulfide on TGH-3Q catalyst and measured adsorption isotherm of carbonyl sulfide and water under the temperature of 20-70 centigrade. They concluded that the adsorption of carbonyl sulfide is dissociative and the adsorption isotherm corresponds with the Freundlich equation. The adsorption isotherm of water also corresponds with the Freundlich equation. However, the adsorption of carbonyl sulfide increases as the temperature increases, while the adsorption of water decreases as the temperature increases. The intrinsic kinetic equation of the hydrolysis is as follows:

$$
\begin{gathered}
R=k C_{\mathrm{COS}}^{1} C_{\mathrm{H}_{2} \mathrm{O}}^{-0.5} \times \frac{1}{1+K C_{\mathrm{CO}_{2}}} \\
k=1.82 \times 10^{14} e^{-75800 / R T} \\
K=486 e^{6000 / R T} .
\end{gathered}
$$

In the equation, $R$ means reaction rate; $k$ means constant of reaction rate; $K$ means adsorption constant of carbon dioxide; $C$ means concentration of reactants.

The equation shows that the catalytic hydrolysis of carbonyl sulfide is a first-order reaction with respect to carbonyl sulfide. And the water is essential as the hydrolytic agent; however, excessive water will impede the reaction process. Besides, the hydrolysis speeds up as the temperature increases. Finally, the hydrolysis of carbonyl sulfide is controlled by surface adsorption.

By adopting the inner-recycle nongradient reactor, Liang et al. [70] studied the catalytic hydrolysis of carbonyl sulfide and found that the possibility of carbonyl sulfide to be adsorbed increases due to the high cycle ratio. Therefore, they concluded that hydrolysis is determined by surface reaction. By adopting the inner-recycle non-gradient reactor under the reducing atmosphere, $\mathrm{Li}$ et al. [73] studied the catalytic hydrolysis of carbonyl sulfide on $\gamma-906$ catalyst and found that the reaction orders of carbonyl sulfide and water are 0.66 and 0.06 , respectively. They held that hydrolysis is controlled by both the internal diffusion and the chemical reaction.

Williams et al. [74] found that the reaction kinetics of carbonyl sulfide also corresponds with the LangmuirHinshelwood equation. They held that the reactants are adsorbed on the surface of the catalyst, and the reaction between adsorbed carbonyl sulfide and water is the controlling step of the hydrolysis. By doing significance analysis, Tong $S$ found that the Eley-Rideal model is more significant to the result compared with the Langmuir-Hinshelwood model.

\section{Reaction Mechanism of COS Hydrolysis}

The main hydrolysis reaction mechanism is shown as follows:

$$
\mathrm{COS}+\mathrm{H}_{2} \mathrm{O} \longrightarrow \mathrm{CO}_{2}+\mathrm{H}_{2} \mathrm{~S}
$$

At present, it is widely believed that the hydrolysis of carbonyl sulfide belongs to base-catalyzed reaction, and the force of the base site has an important effect on the hydrolysis of carbonyl sulfide.

Williams et al. [74] have already studied the effect of surface alkalinity of alkali on the hydrolysis of carbonyl sulfide. They proposed the concerted mechanism to describe the hydrolysis of carbonyl sulfide (Figure 2). They held that hydroxyl and water exist on the surface of catalyst, and carbonyl sulfide is adsorbed due to ion-dipole interaction. The base site is the active site of carbonyl sulfide's hydrolysis.

By adopting the IR spectrum method, Rhodes et al. [61] studied the hydrolysis of carbonyl sulfide on Co-Mo catalyst and found that the surface of the catalyst is covered partly 


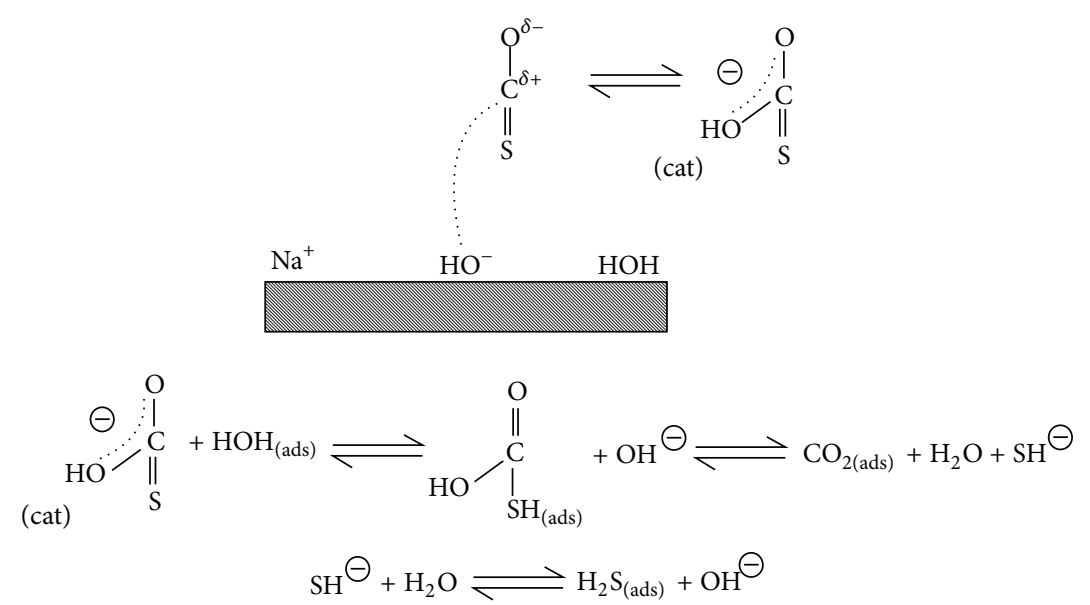

FIGURE 2: The concerted mechanism as proposed by George [23].

by hydroxyl due to the adsorption of water, and the carbonyl sulfide is adsorbed due to ion-dipole interaction. Then, the Hydrogen Thiocarbonate (HTC) is formed. HTC is the intermediate product and will decompose into hydrogen sulfide and carbon dioxide. In the adsorption process, carbonyl sulfide and water are competitive. By adopting the insitu IR technology, Laperdrix et al. [75] studied the hydrolysis of carbonyl sulfide on $\mathrm{Al}_{2} \mathrm{O}_{3}$ catalyst and found that $\mathrm{HTC}$ is formed by the reaction of carbonyl sulfide and hydroxyl is adsorbed on the surface of the catalyst, which enhances the polarization of carbonyl sulfide.

By adopting the IR spectrum method, Fiedorow et al. [65] found that the hydroxyl on the surface of $\mathrm{Al}_{2} \mathrm{O}_{3}$ can adsorb carbonyl sulfide and the intermediate product is thiocarbonate which will decompose rapidly into hydrogen sulfide and carbon dioxide. Hydrogen sulfide and carbon dioxide are competitive in the adsorption process. Furthermore, they discovered that the activity of the catalyst decreases in acidic conditions, while it increases in alkaline conditions. They proposed the following reaction mechanism:

$$
\begin{aligned}
& \mathrm{H}_{2} \mathrm{O}+\Theta \longleftrightarrow \mathrm{H}_{2} \mathrm{O} \cdot \Theta \\
& \mathrm{H}_{2} \mathrm{O} \cdot \Theta+\mathrm{COS}(\mathrm{g}) \longleftrightarrow \mathrm{H}_{2} \mathrm{~S} \cdot \Theta+\mathrm{CO}_{2}(\mathrm{~g}) \\
& \mathrm{H}_{2} \mathrm{~S} \cdot \Theta \longleftrightarrow \mathrm{H}_{2} \mathrm{~S}+\Theta \\
& \Theta \text { : active site. }
\end{aligned}
$$

Wang [76] studied the hydrolysis of carbonyl sulfide on mixed metal oxides and proposed the following hydrolysis mechanism of carbonyl sulfide:

$$
\begin{gathered}
\mathrm{COS}+\Theta=\mathrm{COS} \cdot \Theta \\
\mathrm{H}_{2} \mathrm{O}+\Theta=\mathrm{H}_{2} \mathrm{O} \cdot \Theta \\
\mathrm{H}_{2} \mathrm{O} \cdot \Theta+\operatorname{COS} \cdot \Theta=\mathrm{H}_{2} \mathrm{~S} \cdot \Theta+\mathrm{CO}_{2} \cdot \Theta \\
\mathrm{H}_{2} \mathrm{~S} \cdot \Theta=\mathrm{H}_{2} \mathrm{~S}+\Theta
\end{gathered}
$$

$$
\begin{gathered}
\mathrm{CO}_{2} \cdot \Theta=\mathrm{CO}_{2}+\Theta \\
\Theta: \text { active site. }
\end{gathered}
$$

Additionally, researchers found that the base strength on the surface of the catalyst has an important effect on the hydrolysis of carbonyl sulfide. By adopting the FTIR spectrum and quantum chemistry methods, Hoggan et al. [77] studied the hydrolysis of carbonyl sulfide on $\mathrm{Al}_{2} \mathrm{O}_{3}$ catalyst and found that hydrolysis proceeds much easier on sodium meta aluminate, which does not have bronsted acid. They concluded that carbonyl sulfide is mainly adsorbed on the site of weak base. Li et al. [78] studied the hydrolysis of carbonyl sulfide on alkali-modified $\gamma-\mathrm{Al}_{2} \mathrm{O}_{3}$ catalyst and found that distribution of base strength on the surface of the catalyst is related to the distribution of energy on the surface. They concluded that the effective range of base strength in the hydrolysis is between 4.8 and 9.8 .

By adopting the $\mathrm{CO}_{2}$-TPD, Shangguan and Guo [79] studied the properties of the alkaline site on three kinds of $\mathrm{Al}_{2} \mathrm{O}_{3}$ catalyst and studied the hydrolysis of carbonyl sulfide and carbon disulfide. They found that the kinds, amounts, and strength of alkaline sites are different. The alkalescent site is the active site of the carbonyl sulfide's hydrolysis. The amount and strength of alkalescent site can be increased by supporting $\mathrm{Pt}$ and $\mathrm{K}_{2} \mathrm{O}$ on the surface of the catalyst; thus, the hydrolysis activity of the catalyst can be increased.

Hong He's group conducted in-depth studies on the reaction mechanism of the COS hydrolysis and they have achieved good results. By studying the oxygen toxicity mechanism of catalyst, they found that the hydroxyl on the surface of the catalyst plays an important role in the hydrolysis and the intermediate product is thiocarbonate. They reported that the reaction mechanism of COS on mineral oxides can be summarized as shown in Figure 3.

In Figure 3, gaseous carbon dioxide $\left(\mathrm{CO}_{2}\right)$, hydrogen sulfide $\left(\mathrm{H}_{2} \mathrm{~S}\right)$, sulfur dioxide $\left(\mathrm{SO}_{2}\right)$, surface sulfite $\left(\mathrm{SO}_{3}{ }^{2-}\right)$, and sulfate $\left(\mathrm{SO}_{4}{ }^{2-}\right)$ were found to be the gaseous and surface products, respectively. Hydrogen thiocarbonate $\left(\mathrm{HSCO}_{2}{ }^{-}\right.$, 


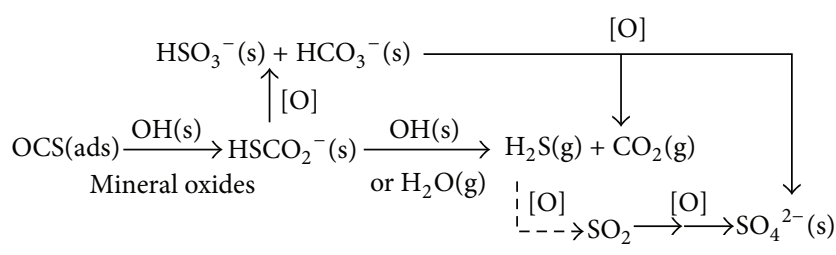

FIGURE 3: The concerted mechanism as proposed by He et al. [9, 2427].

HTC) was proposed to be the crucial intermediate for both the oxidation and the hydrolysis pathway [24-27, 80].

\section{Conclusions}

At present, the catalytic hydrolysis method is the main method to remove carbonyl sulfide. It has many advantages, such as low energy consumption, easy operation and less side reaction. The main task is to develop a new kind of catalyst which is highly active, highly stable, and highly antipoisoning. The catalyst carrier basically has two kinds. One is a delegate with $\mathrm{Al}_{2} \mathrm{O}_{3}$ and $\mathrm{TiO}_{2}$ metal oxides. Another kind of nonmetallic oxide is a delegate with activated carbon. Alkali metal and alkaline earth metal which are supported on $\gamma-\mathrm{Al}_{2} \mathrm{O}_{3}$ can modulate the distribution of the amount of alkali and base intensity. Regarding the production of catalytic hydrolysis of COS, the simple substance $S$ and sulfate can be formed on the catalyst's surface, and the activity of the catalyst decreased when the $\mathrm{S} / \mathrm{SO}_{4}{ }^{2-}$ species accumulated on the catalyst's surface. With the introduction of stringent requirements to reduce the sulfur content in industrial feed gas, the fresh impetus is being given to modifying and improving the existing preparation method of the hydrolysis catalyst. By studying the reaction kinetics and reaction mechanism, researchers can find better ways to develop the catalyst and to establish the desulfurization process. Therefore, the focus of reaction kinetics and reaction mechanism is to establish kinetic models under different conditions and to determine the effect of various kinds of factors and to clarify the path of the reaction.

\section{Acknowledgment}

This work is supported by National Natural Science Foundation (50908110).

\section{References}

[1] E. C. Rupp, E. J. Granite, and D. C. Stanko, "Catalytic formation of carbonyl sulfide during warm gas clean-up of simulated coalderived fuel gas with $\mathrm{Pd} / \gamma-\mathrm{Al}_{2} \mathrm{O}_{3}$ sorbents," Fuel, vol. 92, no. 1, pp. 211-215, 2012.

[2] P. D. N. Svoronost and T. J. Bruno, "Carbonyl sulfide: a review of its chemistry and properties," Industrial and Engineering Chemistry Research, vol. 41, no. 22, pp. 5321-5336, 2002.

[3] P. D. Vaidya and E. Y. Kenig, "Kinetics of carbonyl sulfide reaction with alkanolamines: a review," Chemical Engineering Journal, vol. 148, no. 2-3, pp. 207-211, 2009.
[4] A. Ryzhikov, V. Hulea, D. Tichit et al., "Methyl mercaptan and carbonyl sulfide traces removal through adsorption and catalysis on zeolites and layered double hydroxides," Applied Catalysis A, vol. 397, no. 1-2, pp. 218-224, 2011.

[5] V. Saheb, M. Alizadeh, F. Rezaei, and S. Shahidi, "Quantum chemical and theoretical kinetics studies on the reaction of carbonyl sulfide with $\mathrm{H}, \mathrm{OH}$ and $\mathrm{O}(3 \mathrm{P})$," Computational and Theoretical Chemistry, vol. 994, pp. 25-33, 2012.

[6] N. E. Tsakoumis, M. Rønning, Ø. Borg, E. Rytter, and A. Holmen, "Deactivation of cobalt based Fischer-Tropsch catalysts: a review," Catalysis Today, vol. 154, no. 3-4, pp. 162-182, 2010.

[7] Y. Liu, H. He, and Y. Mu, "Heterogeneous reactivity of carbonyl sulfide on $\alpha-\mathrm{Al}_{2} \mathrm{O}_{3}$ and $\gamma-\mathrm{Al}_{2} \mathrm{O}_{3}$," Atmospheric Environment, vol. 42, no. 6, pp. 960-969, 2008.

[8] V. Saheb, M. Alizadeh, F. Rezaei, and S. Shahidi, "Quantum chemical and theoretical kinetics studies on the reaction of carbonyl sulfide with $\mathrm{H}, \mathrm{OH}$ and $\mathrm{O}(3 \mathrm{P})$," Computational and Theoretical Chemistry, vol. 994, pp. 25-33, 2012.

[9] Y. Liu and H. He, "Experimental and theoretical study of hydrogen thiocarbonate for heterogeneous reaction of carbonyl sulfide on magnesium oxide," Journal of Physical Chemistry A, vol. 113, no. 14, pp. 3387-3394, 2009.

[10] P. J. Crutzen, "The possible importance of CSO for the sulfate layer of the stratosphere," Geophysical Research Letters, vol. 3, pp. 73-76, 1976.

[11] M. Chin and D. D. Davis, "A reanalysis of carbonyl sulfide as a source of stratospheric background sulfur aerosol," Journal of Geophysical Research, vol. 100, no. 5, pp. 8993-9005, 1995.

[12] A. J. Kettle, U. Kuhn, M. Von Hobe, J. Kesselmeier, and M. O. Andreae, "Global budget of atmospheric carbonyl sulfide: temporal and spatial variations of the dominant sources and sinks," Journal of Geophysical Research D, vol. 107, no. 22, article 4658, 2002.

[13] S. A. Montzka, P. Calvert, B. D. Hall et al., "On the global distribution, seasonality, and budget of atmospheric carbonyl sulfide (COS) and some similarities to $\mathrm{CO}_{2}$," Journal of Geophysical Research D, vol. 112, no. 9, Article ID D9302, 2007.

[14] S. F. Watts, "The mass budgets of carbonyl sulfide, dimethyl sulfide, carbon disulfide and hydrogen sulfide," Atmospheric Environment, vol. 34, no. 5, pp. 761-779, 2000.

[15] T. Ogawa, K. Noguchi, M. Saito et al., "Carbonyl sulfide hydrolase from Thiobacillus thioparus strain THI115 is one of the $\beta$ carbonic anhydrase family enzymes," Journal of the American Chemical Society, vol. 135, pp. 3818-3825, 2013.

[16] M. E. Whelan, D. Min, and R. C. Rhew, "Salt marsh vegetation as a carbonyl sulfide (COS) source to the atmosphere," Atmospheric Environment, vol. 73, pp. 131-137, 2013.

[17] X. Wang, J. Qiu, P. Ning et al., "Adsorption/desorption of low concentration of carbonyl sulfide by impregnated activated carbon under micro-oxygen conditions," Journal of Hazardous Materials, vol. 229-230, pp. 128-136, 2012.

[18] W. Afzal, M. P. Breil, I. Tsivintzelis, A. H. Mohammadi, G. M. Kontogeorgis, and D. Richon, "Experimental study and phase equilibrium modeling of systems containing acid gas and glycol," Fluid Phase Equilibria, vol. 318, pp. 40-50, 2012.

[19] K. Sunanda, B. N. Rajasekhar, P. Saraswathy, and B. N. Jagatap, "Photo-absorption studies on carbonyl sulphide in 30,000$91,000 \mathrm{~cm}^{-1}$ region using synchrotron radiation," Journal of Quantitative Spectroscopy and Radiative Transfer, vol. 113, no. 1, pp. 58-66, 2012. 
[20] S. Hattori, J. A. Schmidt, D. W. Mahler, S. O. Danielache, M. S. Johnson, and N. Yoshida, "Isotope effect in the carbonyl sulfide reaction with $\mathrm{O}(3 \mathrm{P})$," Journal of Physical Chemistry A, vol. 116, no. 14, pp. 3521-3526, 2012.

[21] J. Zhang, J. Xiao, Y. Liu, and X. Wei, "Solubility of carbonyl sulfide in aqueous solutions of ethylene glycol at temperatures from (308.15 K to 323.15) K," Journal of Chemical and Engineering Data, vol. 55, no. 11, pp. 5350-5353, 2010.

[22] R. G. Zhang, L. X. Ling, and B. J. Wang, "Density functional theory analysis of carbonyl sulfide hydrolysis: effect of solvation and nucleophile variation," Journal of Molecular Modeling, vol. 18, pp. 1255-1262, 2012.

[23] Z. M. George, "Effect of catalyst basicity for $\mathrm{COS}-\mathrm{SO}_{2}$ and $\mathrm{COS}$ hydrolysis reactions," Journal of Catalysis, vol. 35, no. 2, pp. 218224, 1974.

[24] Y. Liu, H. He, and Y. Mu, "Heterogeneous reactivity of carbonyl sulfide on $\alpha-\mathrm{Al}_{2} \mathrm{O}_{3}$ and $\gamma-\mathrm{Al}_{2} \mathrm{O}_{3}$," Atmospheric Environment, vol. 42, no. 6, pp. 960-969, 2008.

[25] Y. Liu, H. He, W. Xu, and N. Yu, "Mechanism of heterogeneous reaction of carbonyl sulfide on magnesium oxide," Journal of Physical Chemistry A, vol. 111, no. 20, pp. 4333-4339, 2007.

[26] H. He, J. Liu, Y. Mu, Y. Yu, and M. Chen, "Heterogeneous oxidation of carbonyl sulfide on atmospheric particles and alumina," Environmental Science and Technology, vol. 39, no. 24, pp. 9637-9642, 2005.

[27] Y. Liu, H. He, and Q. Ma, "Temperature dependence of the heterogeneous reaction of carbonyl sulfide on magnesium oxide," Journal of Physical Chemistry A, vol. 112, no. 13, pp. 28202826, 2008

[28] J. Shangguan, Y. Zhao, H. Fan, L. Liang, F. Shen, and M. Miao, "Desulfurization behavior of zinc oxide based sorbent modified by the combination of $\mathrm{Al}_{2} \mathrm{O}_{3}$ and $\mathrm{K}_{2} \mathrm{CO}_{3}$," Fuel, vol. 108, pp. 8084, 2013.

[29] L. L. Yu, X. L. Tang, H. H. Yi, and P. Ning, "Medium- and lowtemperature catalytic hydrolysis of carbonyl sulfide," Industrial Catalysis, vol. 17, pp. 21-26, 2009.

[30] J. Xiao, Y. Peng, and A. Xiao, "The development on the technique of hydrolysis of carbonyl sulfide and carbon disulfide at low and ambient temperature," Hubei Chemical, vol. 20, pp. 7-9, 2003

[31] Y. B. Chen, "Investigation and preparation of NCT-1 1 organic sulfur hydrolyst," Journal of Chemical Industry \& Engineering, vol. 18, pp. 9-11, 1997.

[32] G. Centi and S. Perathoner, "Catalysis by layered materials: a review," Microporous and Mesoporous Materials, vol. 107, no. 12, pp. 3-15, 2008.

[33] Y. Wu, Y. Yu, J. Z. Zhou et al., "Effective removal of pyrophosphate by $\mathrm{Ca}-\mathrm{Fe}-\mathrm{LDH}$ and its mechanism," Chemical Engineering Journal, vol. 179, pp. 72-79, 2012.

[34] F. Li, J. Liu, D. G. Evans, and X. Duan, "Stoichiometric synthesis of pure $\mathrm{MFe}_{2} \mathrm{O}_{4}(\mathrm{M}=\mathrm{Mg}$, $\mathrm{Co}$, and $\mathrm{Ni})$ spinel ferrites from tailored layered double hydroxide (hydrotalcite-like) precursors," Chemistry of Materials, vol. 16, no. 8, pp. 1597-1602, 2004.

[35] H. Yi, S. Zhao, X. Tang, P. Ning, H. Wang, and D. He, "Influence of calcination temperature on the hydrolysis of carbonyl sulfide over hydrotalcite-derived $\mathrm{Zn}-\mathrm{Ni}$-Al catalyst," Catalysis Communications, vol. 12, no. 15, pp. 1492-1495, 2011.

[36] S. Zhao, H. Yi, X. Tang, P. Ning, H. Wang, and D. He, "Effect of Ce-doping on catalysts derived from hydrotalcite-like precursors for COS hydrolysis," Journal of Rare Earths, vol. 28, no. 1, pp. 329-333, 2010.
[37] H. Wang, H. Yi, X. Tang et al., "Catalytic hydrolysis of cos over conial mixed oxides modified by lanthanum," Fresenius Environmental Bulletin, vol. 20, no. 3, pp. 773-778, 2011.

[38] H. Wang, H. Yi, P. Ning et al., "Calcined hydrotalcite-like compounds as catalysts for hydrolysis carbonyl sulfide at low temperature," Chemical Engineering Journal, vol. 166, no. 1, pp. 99-104, 2011.

[39] H. Yi, H. Wang, X. Tang et al., "Effect of calcination temperature on catalytic hydrolysis of COS over CoNiAl catalysts derived from hydrotalcite precursor," Industrial and Engineering Chemistry Research, vol. 50, no. 23, pp. 13273-13279, 2011.

[40] H. Y. Wang, H. H. Yi, X. L. Tang et al., "Study of hydrolysis of carbonyl sulfide over mixed oxides from hydrotalcite-like compounds," Chinese Journal of Environmental Engineering, vol. 6, pp. 545-549, 2012.

[41] S. Zhao, H. Yi, X. Tang et al., "Characterization of $\mathrm{Zn}-\mathrm{Ni}-$ Fe hydrotalcite-derived oxides and their application in the hydrolysis of carbonyl sulfide," Applied Clay Science, vol. 56, pp. 84-89, 2012.

[42] H. Y. Wang, H. H. Yi, X. L. Tang et al., "Catalytic hydrolysis of COS over calcined CoNiAl hydrotalcite-like compounds modified by cerium," Applied Clay Science, vol. 70, pp. 8-13, 2012.

[43] S. Z. Zhao, H. H. Yi, X. L. Tang, and C. Y. Song, "Low temperature hydrolysis of carbonyl sulfide using $\mathrm{Zn}-\mathrm{Al}$ hydrotalcitederived catalysts," Chemical Engineering Journal, vol. 226, pp. 161-165, 2013.

[44] X. Wang, L. Ding, Z. Zhao, W. Xu, B. Meng, and J. Qiu, "Novel hydrodesulfurization nano-catalysts derived from $\mathrm{Co}_{3} \mathrm{O}_{4}$ nanocrystals with different shapes," Catalysis Today, vol. 175, no. 1, pp. 509-514, 2011.

[45] L. T. Liang, The Study on Modified Alumina Based Catalyst for Hish Concentration Carbonyl Sulfide Hydrolysis, Taiyuan University of Technology, Taiyuan, China, 2005.

[46] J. Zhang and X. Li, "The research of removing COS at low temperature by modified active carbon," Liaoning Chemical Industry, vol. 3, pp. 102-104, 1998.

[47] D. He, H. Yi, X. Tang et al., "The catalytic hydrolysis of carbon disulfide on $\mathrm{Fe}-\mathrm{Cu}-\mathrm{Ni} / \mathrm{AC}$ catalyst at low temperature," Journal of Molecular Catalysis A, vol. 357, pp. 44-49, 2012.

[48] D. He, H. Yi, X. Tang, P. Ning, H. Wang, and S. Zhao, "Carbon disulfide hydrolysis over $\mathrm{Fe}-\mathrm{Cu} / \mathrm{AC}$ catalyst modified by cerium and lanthanum at low temperature," Journal of Rare Earths, vol. 28, no. 1, pp. 343-346, 2010.

[49] N. Ping, Y. Lili, Y. Honghong et al., "Effect of Fe/Cu/Ce loading on the coal-based activated carbons for hydrolysis of carbonyl sulfide," Journal of Rare Earths, vol. 28, no. 2, pp. 205-210, 2010.

[50] P. Ning, K. Li, H. H. Yi et al., "Simultaneous catalytic hydrolysis of carbonyl sul fide and carbon disulfide over modified microwave coal-based active carbon catalysts at low temperature," The Journal of Physical Chemistry C, vol. 116, pp. 1705517062, 2012.

[51] H. Yi, D. He, X. Tang, H. Wang, S. Zhao, and K. Li, "Effects of preparation conditions for active carbon-based catalyst on catalytic hydrolysis of carbon disulfide," Fuel, vol. 97, pp. 337343, 2012.

[52] M. Yan, Z. Xiao, and Y. Zhang, "Reaction of COS hydrolysis over La-A1/Cordierite honeycomb catalyst," Journal of East China University of Science and Technology, vol. 31, no. 1, pp. 7130-7132, 2005. 
[53] W. Li, W. Shudong, and Y. Quan, "Removal of carbonyl sulide at low temperature: experiment and modeling," Fuel Processing Technology, vol. 91, no. 7, pp. 777-782, 2010.

[54] S. Tan, C. Li, S. Liang, and H. Guo, "Compensation effect in catalytic hydrolysis of carbonyl sulfide at lower temperature compensation effect in COS hydrolysis," Catalysis Letters, vol. 8, no. 2-4, pp. 155-168, 1991.

[55] S. Tong, Catalytic Hydrolysis of Carbon Disulfide and Carbonyl Sulifde, University of Alderta, Edmonton, Canada, 1992.

[56] J. West, B. P. Williams, N. C. Young, C. Rhodes, and G. J. Hutchings, "New directions for COS hydrolysis: low temperature alumina catalysts," Studies in Surface Science and Catalysis, vol. 119, pp. 373-378, 1998.

[57] J. West, B. P. Williams, N. Young, C. Rhodes, and G. J. Hutchings, "Ni- and $\mathrm{Zn}$-promotion of $\gamma-\mathrm{Al}_{2} \mathrm{O}_{3}$ for the hydrolysis of COS under mild conditions," Catalysis Communications, vol. 2, no. 3-4, pp. 135-138, 2001.

[58] F. Wang, H. Zhao, D. Zhang, and J. Gao, "Desulfurization mechanism of iron-manganese compound oxide desulfurizer for removal of COS from coal gas," Journal of the China Coal Society, vol. 2, pp. 197-200, 2008.

[59] Z. Gao, L. Yin, C. Li, and K. Xie, "Study on simultaneous removal of $\mathrm{COS}$ and $\mathrm{H}_{2} \mathrm{~S}$ by using $\alpha$-FeOOH nanoparticle," Journal of Fuel Chemistry and Technology, vol. 31, no. 3, pp. 249253, 2003.

[60] Z. Gao and C. Li, "The effect of preparation condition of active component on activity of COS hydrolysis," Coal Conversion, vol. 7, pp. 91-95, 1997.

[61] C. Rhodes, S. A. Riddel, J. West, B. P. Williams, and G. J. Hutchings, "Low-temperature hydrolysis of carbonyl sulfide and carbon disulfide: a review," Catalysis Today, vol. 59, no. 3 , pp. 443-464, 2000.

[62] Y. Zhang, Z. Xiao, and J. Ma, "Hydrolysis of earbonyl sulfide over sulfidized rare earth oxides," Joumal of Fudan University, vol. 42, pp. 372-374, 2003.

[63] Y. Zhang, Z. Xiao, and J. Ma, "Hydrolysis of COS over rare earth oxysulfides," Chemical Research in Chinese Universities, vol. 25, pp. 721-724, 2004.

[64] Y. Zhang, Z. Xiao, and J. Ma, "Efect of $\mathrm{O}_{2}$ an $\mathrm{d} \mathrm{SO}_{2}$ on hydrolysis of carbonyl sulfide over rare earth oxysulfides," Journal of Fudan University, vol. 42, pp. 379-380, 2003.

[65] R. Fiedorow, R. Léauté, and I. G. D. Lana, "A study of the kinetics and mechanism of COS hydrolysis over alumina," Journal of Catalysis, vol. 85, no. 2, pp. 339-348, 1984.

[66] Z. M. George, "Kinetics of cobalt-molybdate-catalyzed reactions of $\mathrm{SO}_{2}$ with $\mathrm{H}_{2} \mathrm{~S}$ and COS and the hydrolysis of COS," Journal of Catalysis, vol. 32, no. 2, pp. 261-271, 1974.

[67] S. Tong, I. G. D. Lana, and K. T. Chuang, "Kinetic modelling of the hydrolysis of carbonyl sulfide catalyzed by either titania or alumina," Canadian Journal of Chemical Engineering, vol. 71, no. 3, pp. 392-400, 1993.

[68] V. Chan and G. Dalld, "On the catalytic hydrolysis of carbonyl sulfide over gamma-alumina," Canadian Journal of Chemical Engineering, vol. 56, pp. 751-753, 1978.

[69] Z. Miroslav, "Heterogenously catalyzed hydrolysis of carbonyl sulfide," Chemicky Prumysl, vol. 24, pp. 549-552, 1974.

[70] M. Liang, C. Li, and H. Guo, "Study on reaction kinetics of COS hydrolysis at lower temperature," Chinese Journal of Catalysis, vol. 23, pp. 357-362, 2002.

[71] J. Y. Lin, H. X. Guo, and K. C. Xie, "Studies on the deactivation of carbonyl sulfide hydrolysis catast," Journal of Ningxia University, vol. 22, pp. 192-194, 2001.
[72] H. X. Guo, M. Q. Miao, and Y. Q. Zhang, "performance of TGH3Q COS hydrolysis catalyst at ambient and low temperature," Industrial Catalysis, vol. 5, pp. 37-43, 1999.

[73] J. W. Li, C. Li, and J. Liu, "Study on COS hydrolysis kinetics on $\gamma$-906 catalyst in reducing atmosphere," Industrial Catalysis, vol. 2, pp. 23-29, 1996.

[74] B. P. Williams, N. C. Young, J. West, C. Rhodes, and G. J. Hutchings, "Carbonyl sulphide hydrolysis using alumina catalysts," Catalysis Today, vol. 49, no. 1-3, pp. 99-104, 1999.

[75] E. Laperdrix, I. Justin, G. Costentin et al., "Comparative study of $\mathrm{CS}_{2}$ hydrolysis catalyzed by alumina and titania," Applied Catalysis B, vol. 17, no. 1-2, pp. 167-173, 1998.

[76] H. N. Wang, "Preparetion of catalyst and research of kinetics for carbonyl sulfide hydrolysis under moderate temperature," Taiyuan University of Technology, vol. 2, pp. 23-29, 1996.

[77] P. E. Hoggan, A. Aboulayt, A. Pieplu, P. Nortier, and J. C. Lavalley, "Mechanism of COS hydrolysis on alumina," Journal of Catalysis, vol. 149, no. 2, pp. 300-306, 1994.

[78] C. H. Li, H. X. Guo, and S. S. Tan, "Study on the alkalized $\gamma$ $\mathrm{Al}_{2} \mathrm{O}_{3}$ catalyst for its base strength distribution and catalytic activity," Journal of Molecular Catalysis, vol. 8, pp. 305-311, 1994.

[79] J. Shangguan and H. X. Guo, "The surface basicity and catalysis over the alumina based catalysts for COS and $\mathrm{CS}_{2}$ hydrolysis," Journal of Molecular Catalysis, vol. 11, pp. 337-342, 1997.

[80] J. Liu, Y. Yu, Y. Mu, and H. He, "Mechanism of heterogeneous oxidation of carbonyl sulfide on $\mathrm{Al}_{2} \mathrm{O}_{3}$ : an in Situ diffuse reflectance infrared fourier transform spectroscopy investigation," Journal of Physical Chemistry B, vol. 110, no. 7, pp. 32253230, 2006. 

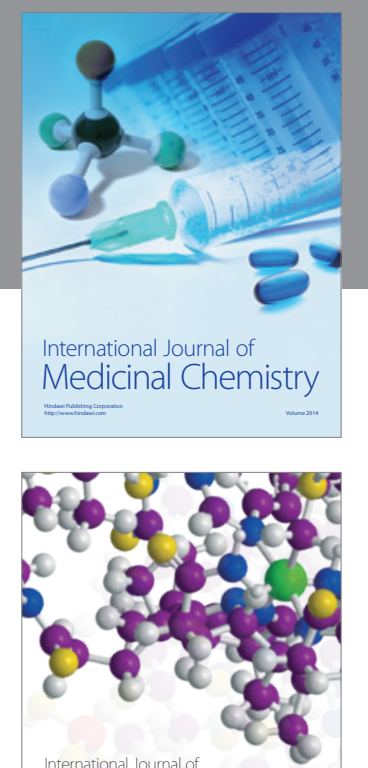

\section{Carbohydrate} Chemistry

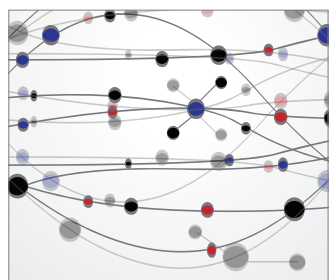

The Scientific World Journal
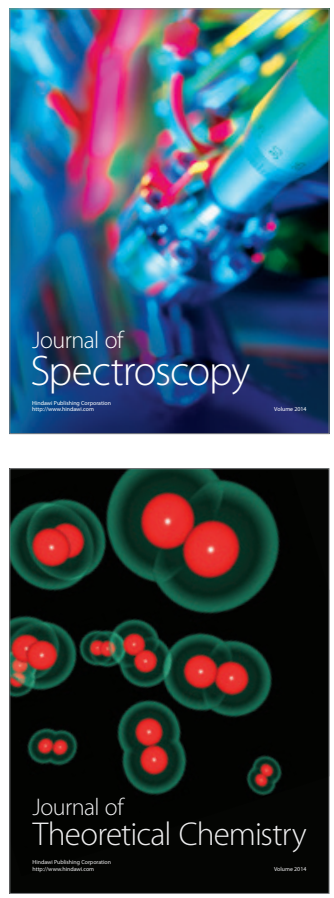
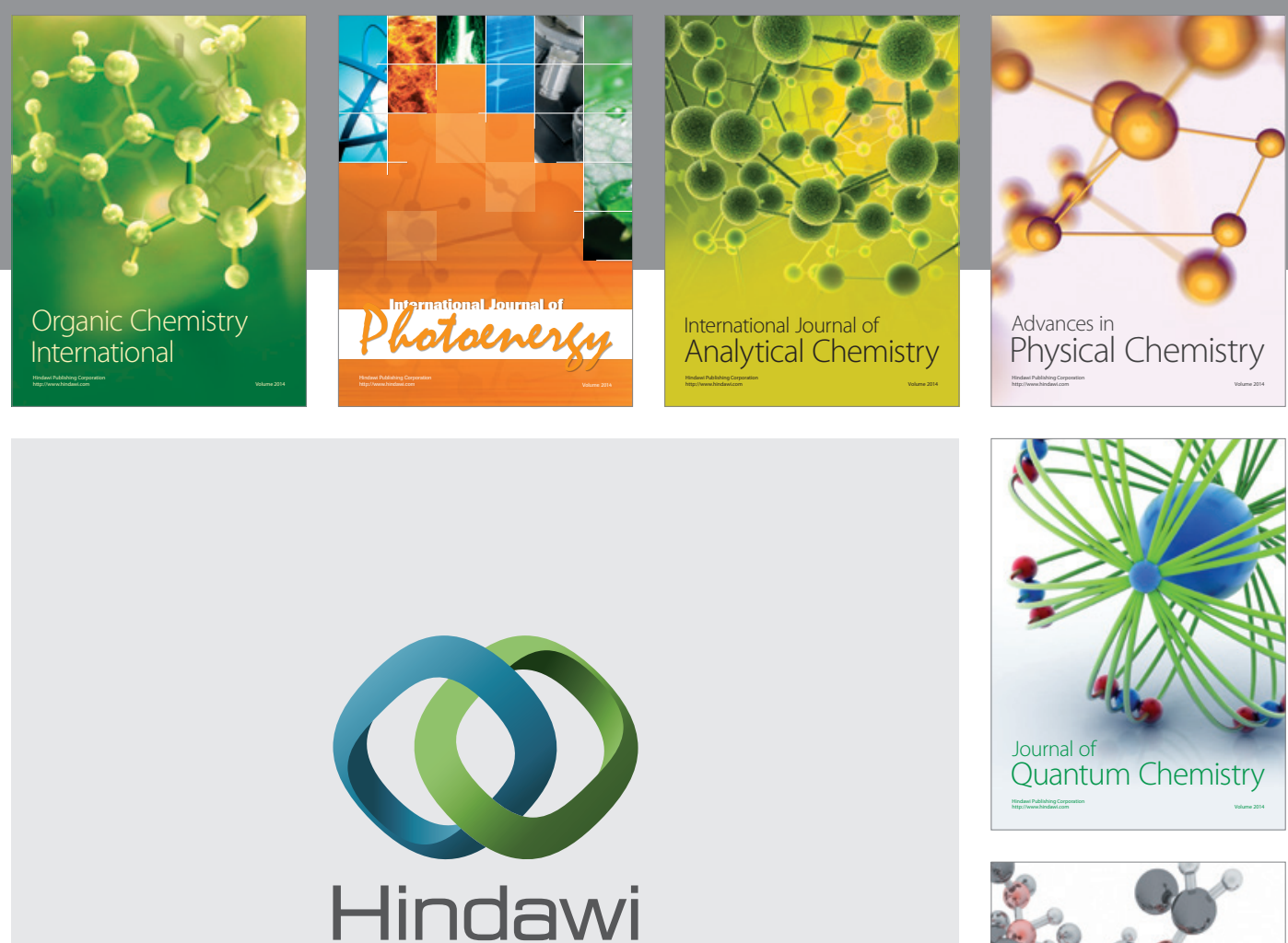

Submit your manuscripts at

http://www.hindawi.com

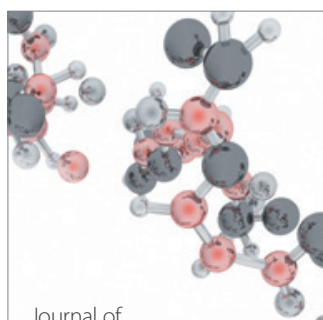

Analytical Methods

in Chemistry

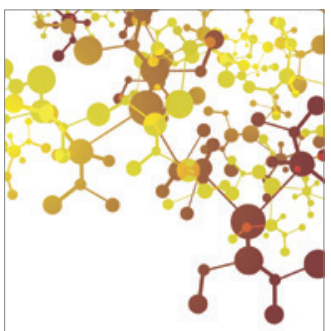

Journal of

Applied Chemistry

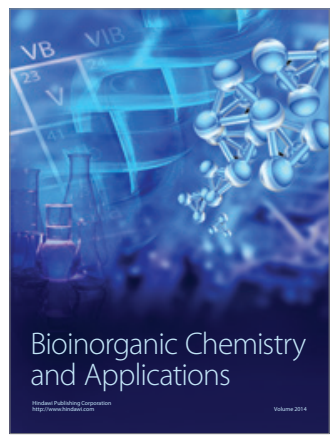

Inorganic Chemistry
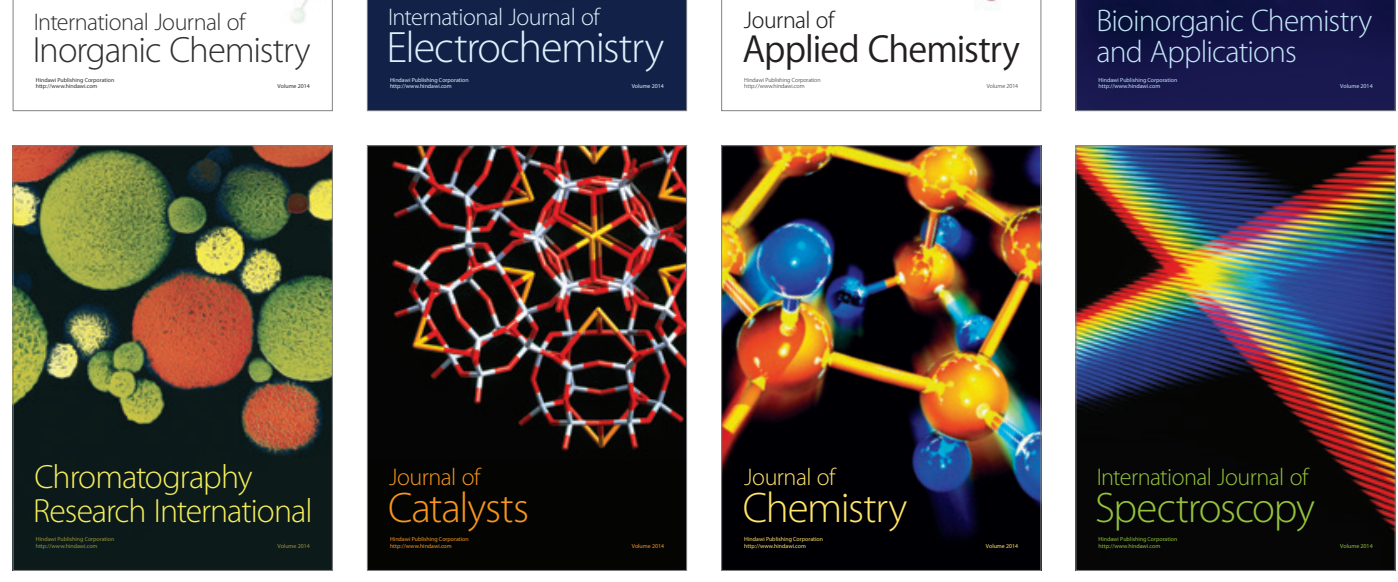